\title{
Los espacios de kiwi: productores y organización de la producción en el sudeste bonaerense
}

Kiwi spaces: producers and production organization in the southeast of Buenos Aires province

\author{
Silvia Liliana Bocero \\ Grupo de Investigación Desarrollo Rural, Ambiente y Geotecnologías, \\ Facultad de Humanidades, Universidad Nacional de Mar del Plata, \\ Argentina \\ slbocero@mdp.edu.ar \\ Andrea Claudia Bonnet \\ Grupo de Investigación Desarrollo Rural, Ambiente y Geotecnologías, \\ Facultad de Humanidades, Universidad Nacional de Mar del Plata, \\ Argentina \\ anclabo@hotmail.com
}

\section{Resumen:}

El cultivo de kiwi se inscribe en el contexto de los profundos cambios que experimentó el sector agroalimentario desde la década del noventa. El objetivo del presente trabajo es revelar las particularidades que asume una producción no tradicional como el kiwi en el sudeste bonaerense, a través de la identificación y caracterización de los productores y de las modalidades de organización social de la producción adoptadas. La estrategia metodológica ha sido fundamentalmente cualitativa: se realizaron entrevistas semiestructuradas a una variedad de informantes calificados - fundamentalmente productores y trabajadores- y se complementaron con observación participante en explotaciones y empaques frutícolas. Los resultados muestran el ingreso de nuevos agentes a la producción agraria, requerimientos de calidad en la producción, empresas que integran actividades de poscosecha, inserciones laborales intermitentes y eventuales y la permanencia de características propias de la precariedad tradicional en el agro.

Palabras ClaVe: Fruticultura, Nuevos productores, Organización de la producción.

\section{AbstraCt:}

The kiwi fruit cultivation is inscribed within the context of deep changes that the agri-food sector experimented since the 1990 s. The objective of the present work is to reveal the particularities assumed by a non-traditional production like the kiwi fruit, in the southeast of Buenos Aires province, through the identification and characterization of the producers and the social organization modalities of production adopted. The methodological strategy has been fundamentally qualitative. Semi-structured interviews were realized to a variety of qualified informants, mainly producers and workers, complemented by participant observation in farms and packing of fruits. The results show the entry of new agents to the agricultural production, quality requirements in the production, companies that integrate post-harvest activities, intermittent and eventual labour insertions and the permanence of traditional characteristics that belong to the precariousness of the agricultural sector.

KEYWORDS: Fruit-growing, New producers, Production organization.

\section{INTRODUCCIÓN}

El cultivo de kiwi se inscribe en el contexto de los profundos cambios que experimentó el sector agroalimentario desde la década del noventa. En el sudeste bonaerense, estos procesos muestran una heterogeneidad en los entramados que se van configurando con el ingreso de nuevos actores a la producción agraria, actores con disposición a invertir y a tomar riesgos y que portan ciertos rasgos que los diferencian de los productores locales.

La producción de kiwi se extiende en la provincia de Buenos Aires desde el noreste, en los partidos que forman el corredor de la costa del río Paraná (San Pedro y Baradero, principalmente), pasando por La Plata, 
hasta General Pueyrredón y General Alvarado en el sudeste. Si bien son pocos los agentes que intervienen en esta actividad en la Argentina, en la zona del sudeste se ha conformado en la actualidad un espacio productivo de kiwi que evidencia un gran potencial y que cuenta con plantaciones de expansión reciente, muchas de la cuales aún están en pleno crecimiento.

El objetivo del presente trabajo es revelar las particularidades que asume una producción no tradicional como el kiwi, a través de la identificación y caracterización de los productores y del análisis de las modalidades de organización social de la producción adoptadas. El artículo está estructurado en cuatro secciones: en primer término se aborda la propuesta teórica y metodológica; a continuación se plantea la configuración socio-territorial del kiwi en el sudeste bonaerense para luego abordar la caracterización de los productores y, por último, las modalidades de organización de la producción.

\section{Perspectivas teóricas y metodológicas}

El cultivo de kiwi se inserta en el marco de transformaciones caracterizadas por fuertes procesos de reestructuración, cambio tecnológico y aumento de escalas productivas. La inclusión de cultivos de alto valor, entre ellos el kiwi y las frutas finas (fundamentalmente la frutilla), aparece como un aspecto novedoso en el sudeste bonaerense. En este sentido,

Un rasgo que define a este tipo de actividades es que dan lugar a productos de alto valor, dirigidos a nichos o segmentos específicos del mercado. Suelen ser producciones intensivas, integradas en cadenas productivas altamente especializadas, involucrando no sólo transformaciones agroindustriales sino también servicios personales y productivos relativamente complejos, así como sofisticados canales de distribución, comunicaciones y embalaje. Estos productos no sólo se orientan a la exportación, como es la percepción generalizada, sino también hacia el sector del mercado interno conformado por los grupos de consumidores de ingresos medio-altos y altos, en gran medida radicados en los centros urbanos (Craviotti, 2004:28).

Como señala Craviotti (2012:144) en su análisis sobre la expansión de otro cultivo de alto valor -el arándano- en Entre Ríos:

Cabe asumir que el proceso de incorporación/desincorporación de las sociedades locales a estos circuitos de abastecimiento no constituye un proceso homogéneo y exento de conflictos, en tanto en la organización de estas cadenas participan diferentes grupos (empresas, productores agrícolas, trabajadores, organismos del Estado y consumidores), que se caracterizan por su heterogeneidad y diversidad de intereses, los cuales entran a menudo en contradicción (Arce \& Booth, 1993; Fletes Ocón, 2006). Tales antagonismos en parte se vinculan con las diferentes posiciones ocupadas en la cadena, y también con la existencia de dos lógicas opuestas: una sectorial/global de acumulación y otra de índole territorial basada en la creación o consolidación de las ventajas específicas locales (Gutman \& Gorenstein, 2003).

Si bien la producción de kiwi desde sus inicios se planteó en relación a una inserción plena en los circuitos globalizados de fruta fresca, su evolución no estuvo en función de la demanda de exportación en contraestación. ${ }^{1}$ A partir de la salida de la convertibilidad en el año 2002, se inicia un proceso que conlleva la ampliación de la superficie dedicada a su cultivo y un aumento de los productores y por el cual se empieza a configurar un entramado de relaciones entre agentes locales y extralocales. Este proceso debe analizarse entendiendo que "el territorio es el resultado de una construcción social y política, en la cual los actores individuales y colectivos intercambian recursos, ejercen poder y articulan intereses” (Radonich, Steimbreger \& Kreiter, 2005).

Los procesos de reestructuración de la agricultura en el contexto de la globalización

(...) afectan la organización de la producción y del trabajo de manera significativa y novedosa a la vez. En primer lugar, contrariamente a un proceso de cambio de tipo unidireccional como el que fuera concebido en la etapa de la modernización, se presentan combinaciones diversas que incluyen en diferente medida cambios tecnológicos, crecientes requerimientos de calidad de la producción, nuevos requisitos de calificaciones y de competencias, la profundización de la precariedad laboral, creciente residencia urbana y multiocupación de los trabajadores, que pueden interactuar de manera diversa e inclusive de forma superpuesta o aparentemente contradictoria (Neiman, 2010:3-4). 
Las implicancias de estas transformaciones impactan en la organización laboral de los establecimientos y en los mercados de trabajo involucrados en la producción de kiwi.

El presente artículo forma parte del proyecto de investigación "Nuevas configuraciones socio-productivas y territoriales: la producción frutícola en el sudeste bonaerense". ${ }^{2}$ El enfoque teórico del proyecto aborda los aspectos estructurales de los agentes y sus interacciones. Se recurre a la perspectiva de los entornos con disposición innovativa, que pone de relieve la institucionalidad local y las redes como dispositivos que favorecen la transmisión del conocimiento (Becattini, 1992; Albornoz, Milesi \& Yoguel, 2004; Gereffi, Humphrey \& Sturgeon, 2005). Se considera el análisis de tramas sociales, ya que el mismo demanda identificar los actores individuales, colectivos e institucionales que intervienen en la producciónreproducción del territorio y las relaciones que se construyen en función de las distintas estrategias que elaboran los actores participantes (Radonich, Steimbreger \& Kreiter, 2005). En el marco analítico propuesto se observa la específica interrelación que se establece entre los planos local y global y la posición de los agentes, así como las diferentes trayectorias locales y las formas que asume el conflicto entre los actores.

La estrategia metodológica ha sido fundamentalmente cualitativa. Se realizaron entrevistas semiestructuradas a una variedad de informantes calificados, siendo fundamentalmente el eje del trabajo la indagación a los productores de kiwi y a los trabajadores, apoyadas con observación participante en explotaciones y empaques frutícolas. Las entrevistas se llevaron a cabo entre los años 2016 y 2018 y se complementaron con la identificación y procesamiento de imágenes satelitales (Google Earth Pro), a los efectos de detectar y evaluar la localización y superficie de las explotaciones. Se incluyó el relevamiento de material bibliográfico y periodístico, así como datos aportados por el Registro Nacional Sanitario de Productores Agropecuarios (RENSPA) y la Cámara de Productores de Kiwi de Mar del Plata.

\section{NUEVAS CONFIGURACIONES SOCIO-TERRITORIALES: EL KIWI EN EL SUDESTE BONAERENSE}

A partir de la salida de la paridad cambiaria se genera un proceso de expansión del cultivo, centrado fundamentalmente en el sudeste de la provincia de Buenos Aires (partidos de General Pueyrredón, General Alvarado, Balcarce, General Madariaga y Mar Chiquita) (Figura 1). De este modo, con aproximadamente 900 hectáreas, la producción de kiwi en nuestro país se encuentra en crecimiento. En el sudeste bonaerense, el partido de General Pueyrredón abarca cerca del $80 \%$ de la superficie implantada (Figura 2) en áreas tradicionalmente hortícolas, como Laguna y Sierra de los Padres, La Gloria y El Boquerón, entre otras.

Este cultivo se analiza en el marco de las transformaciones que han sufrido los sistemas agroalimentarios en las últimas décadas, que se profundizaron a partir de las demandas de una economía crecientemente globalizada. Si bien el kiwi en Argentina se encuentra en la actualidad en una etapa emergente, y su crecimiento ha estado ligado a la demanda del mercado interno (el país es un fuerte importador del producto), tanto en la etapa de inserción del cultivo como en la de su expansión se evidencia que en estas construcciones territoriales intervienen agentes que interactúan en distintas escalas.

Actualmente la actividad se revitaliza: está regida por inversiones significativas y muchos de los agentes que la emprenden son ajenos al sector agrario. Además, da cuenta de la existencia de empresas que integran actividades de poscosecha y de la inserción de firmas comercializadoras extralocales en el espacio productivo considerado. El entramado que va emergiendo alrededor del kiwi es diverso: incluye productores (y su representación sectorial), trabajadores, organismos públicos de $\mathrm{I}+\mathrm{D}$, viveristas, proveedores de insumos, empacadores, comercializadores, profesionales privados y vinculaciones con los ámbitos políticoadministrativo y financiero. En este sentido, las perspectivas sobre la configuración de medios innovadores y sistemas locales de empresas acentúan el carácter colectivo de la innovación,

(...) estos enfoques hacen hincapié en la existencia de un clima social e institucional favorable, considerando como rasgos fundamentales la dinámica de aprendizaje y el grado de interacción existente entre los agentes de un territorio. Si los agentes operan de forma aislada difícilmente pueda hablarse de un medio innovador (Craviotti, 2008:153). 
FIGURA 1:

Partidos del Sudeste Bonaerense según superficie implantada con kiwi

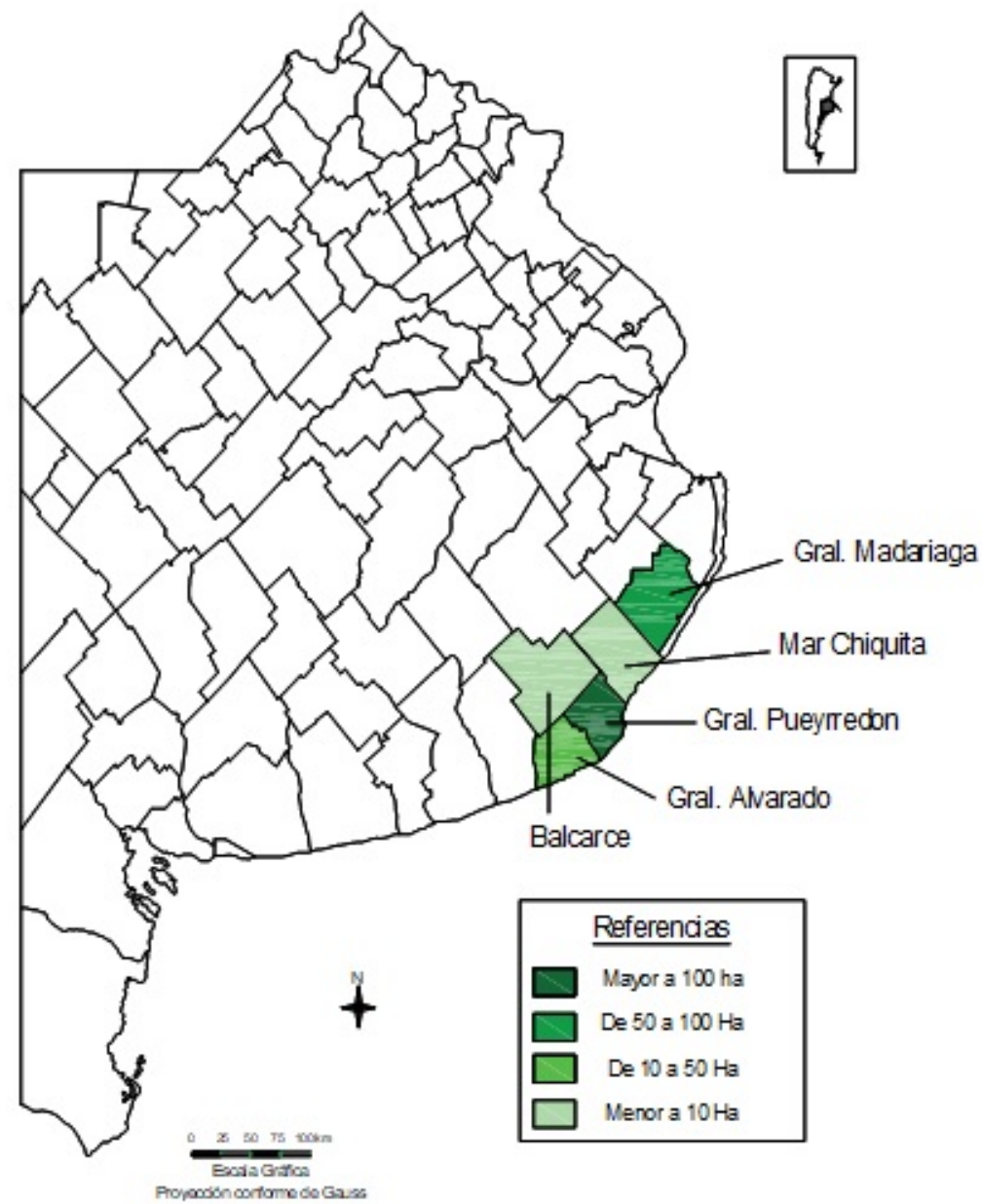

Fuente: Elaboración propia

FIGURA 2

Partidos del Sudeste Bonaerense segn porcentaje de kiwi implantado

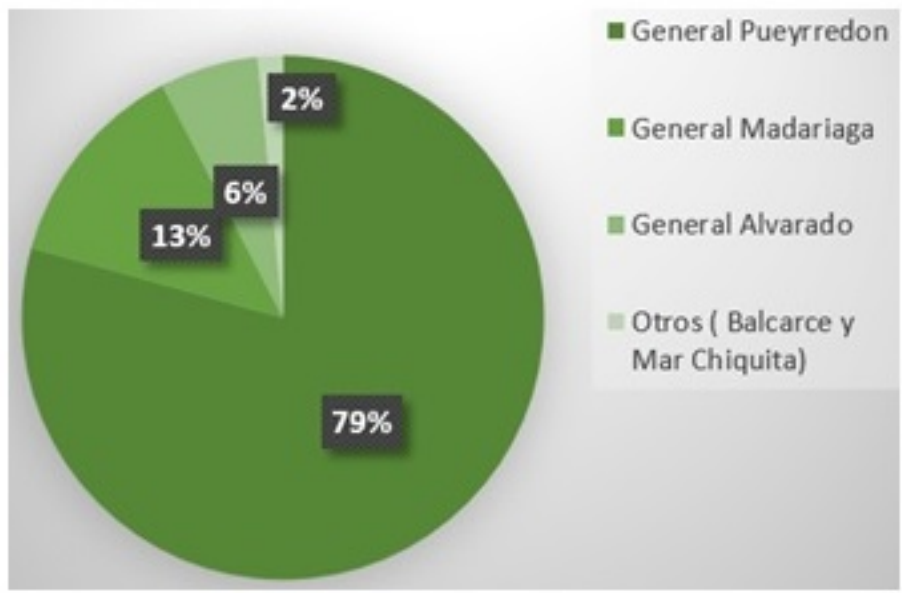

Fuente: Elaboración propia 


\section{Caracterización de lOS PRODUCTORES DE KIWI}

Los productores de kiwi del sudeste bonaerense incluyen desde pequeños hasta grandes inversores, que se asocian con empresas comercializadoras. Se cuentan también productores preexistentes en el área objeto de estudio, que generalmente provienen de producciones intensivas. ${ }^{3}$

En el caso de los productores preexistentes la incorporación del cultivo es limitada, situación que pone de manifiesto el ingreso de nuevos agentes a la producción agropecuaria. Del total de los productores relevados, aproximadamente entre un 55 y $60 \%$ pueden definirse como ingresantes, condición dada fundamentalmente por la trayectoria ocupacional externa al sector agropecuario. Para estos agentes, o bien el kiwi constituyó su actividad productiva inicial o bien fue incorporado a continuación o en conjunto con otro cultivo de alto valor.

Los productores de hasta 10 ha comprenden el 77,3\% de los casos, y son estos actores los que explican el crecimiento en cantidad de productores; mientras que la expansión en hectáreas es expresada por los productores de más de 20 ha que representan el 63,3\% de la superficie implantada (Tabla 1). Los datos mencionados son el resultado del relevamiento llevado a cabo hasta julio de $2018 \mathrm{y}$, si bien son producto de un trabajo exhaustivo, incluyen en algunos casos valores aproximados.

TABLA 1

Cantidad de explotaciones, superficie implantada con kiwi y superficie promedio por escala de extensión en los partidos del Sudeste Bonaerense

\begin{tabular}{|l|c|c|c|c|c|}
\hline Escala & $\begin{array}{c}\text { Cantidad de } \\
\text { Explotaciones }\end{array}$ & $\begin{array}{c}\text { Superficie } \\
\text { Implantada } \\
\text { (ha) }\end{array}$ & $\begin{array}{c}\text { Superfici } \\
\text { e } \\
\text { Promedio } \\
\text { (ha) }\end{array}$ \\
\hline $\mathbf{0 - 1 0}$ & 34 & $\begin{array}{c}77, \\
3\end{array}$ & 136,5 & $\begin{array}{l}26, \\
3\end{array}$ & 4 \\
\hline $\mathbf{1 0 - 2 0}$ & 3 & 6,8 & 54 & $\begin{array}{l}10, \\
4\end{array}$ & 18 \\
\hline $\mathbf{2 0}-$ & 5 & 11,4 & 156 & $\begin{array}{l}30, \\
1\end{array}$ & 31,2 \\
\hline $\begin{array}{l}\text { Más de } \\
\mathbf{5 0}\end{array}$ & 2 & 4,5 & 172 & $\begin{array}{l}33, \\
2\end{array}$ & 86 \\
\hline Total & 44 & 100 & 518,5 & 100 & 11,8 \\
\hline
\end{tabular}

Fuente: Elaboración propia con información proveniente de las distintas fuentes relevadas, actualizada al mes de julio de 2018.

En el estrato de los productores de hasta de 10 ha sólo un número reducido alcanza la unidad económica estimada en el momento de la investigación. ${ }^{4}$

En este universo es posible encontrar agentes monoproductores con actividades no agropecuarias que encaran pequeños emprendimientos de kiwi. Se trata de profesionales sin antecedentes previos en la actividad (tales como abogado, médico, ex deportista, diseñador gráfico, licenciado en marketing, etc.) o bien de empresarios que provienen de distintos ámbitos: pesquero, naviero, inmobiliario, financiero, de la construcción, etc. También se visualizan agentes que tienen los mismos orígenes, pero que comenzaron con otra u otras producciones no tradicionales (cerezas, arándanos, espárragos, etc.) a las cuales mantuvieron o que directamente iniciaron un proceso de reconversión hacia el kiwi. En otros casos se identifican agentes que además de tener el kiwi como único cultivo, emprenden actividades que se vinculan con éste de distintas maneras: venta de insumos agrícolas, de casuarinas, comercialización de frutas y hortalizas, asesoramiento 
técnico, etc. Por último, en este estrato convive un número menor de productores preexistentes, como horticultores, productores avícolas, de miel y muy pocos extensivos.

En cuanto a la forma jurídica, en primer lugar se trata de personas físicas y en segundo lugar de sociedades. En muchos de estos casos recurren a capitales personales o familiares como estrategia para realizar las inversiones. El lugar de residencia de estos productores es fundamentalmente Mar del Plata, a la que le siguen la Ciudad Autónoma de Buenos Aires y Miramar; en muy pocos casos residen en la explotación.

Estos agentes tercerizan las actividades de poscosecha y conservación como el empaque y el enfriamiento; es decir que contratan para estas tareas a las empresas prestadoras de dichos servicios e incluso venden a las mismas directamente su producción.

Entre los productores de kiwi que se ubican por encima de las 10 ha existen empresas que integran actividades de poscosecha: disponen de empaque y cámara de frío y manejan la comercialización.

Existen cinco galpones de empaque: dos están equipados con sistemas de frío de alta tecnología con capacidad para brindar servicios a terceros y los tres restantes cuentan con cámaras frigoríficas de mediana tecnología. Junto al desarrollo de la fase agraria se ha ido generando la infraestructura de empaque y frío así como una serie de servicios asociados que incluyen, por ejemplo, asesores especializados en el cultivo.

La sociedad aparece como la forma jurídica dominante en estos estratos.

Entre estos agentes se destaca un grupo empresario que da cuenta de la existencia de firmas jurídicamente distintas (explotaciones de kiwi y empaque) en las que existen socios comunes, que además participan en más de un eslabón de la cadena. Llevan adelante una gestión unificada a través del mismo administrador y un uso común de algunos recursos productivos. Estos establecimientos provienen de sectores extra-agrarios, de empresas cuya actividad principal es la construcción de proyectos de servicio público, y se vinculan con una empresa exportadora de frutas frescas que se localiza en el norte de la Patagonia (o bien socios de esta empresa integran alguna de las sociedades antes mencionadas).

La Empresa Patagonian Fruits Trade S.A. (2017) señala en su sitio de internet:

En la provincia de Buenos Aires (Balcarce y Sierra de los Padres) Patagonian Fruits Trade encuentra las condiciones ideales -uno de los suelos más ricos del mundo, humedad relativa y clima en general- para la producción de dos variedades emblemáticas del mercado de kiwi. De esta manera, produce de forma exclusiva en la República Argentina la variedad Jingold, además de la Hayward, también muy requerida a nivel global.

Es interesante destacar que si bien la variedad Hayward (pulpa verde) es la que se difunde en el país, recientemente, la citada empresa y el consorcio italiano KiwiGold concertaron un acuerdo estratégico para la producción de kiwi orgánico de la variedad Jintao, de pulpa amarilla.

Otra empresa que data de los inicios del kiwi en el sudeste bonaerense, se asoció desde el año 2012 con una firma italiana productora y comercializadora de fruta fresca. Se incorporó Kiwi Tre Castelli, posibilitando la modernización y la construcción de un galpón de empaque e instalaciones de frío, situación que les permitió estar presentes en los centros de distribución del norte de Italia. En el año 2016 esta unión comercial llegó a su fin y la empresa se vendió en su totalidad a los capitales italianos. ${ }^{5}$ Esta y algunas otras empresas trabajan con convenios de exportación/importación, exportando fruta de la zona y recibiendo fruta de contraestación.

La presencia de capital extranjero, básicamente italiano, se constata en varios eslabones. Entre otras empresas también de capitales extra-locales que se abocan al empaque, enfriamiento y comercialización del kiwi, uno de los casos refiere a una firma cuyo capital proviene de actividades industriales (fabricación de bienes de capital, máquinas y equipos para distintos sectores industriales) que además de kiwi lleva adelante producción extensiva - no en forma directa-, la cual está asociada a la superficie del campo (si bien la compra del mismo y su elección estuvieron focalizados en este cultivo no tradicional). Otro caso es el de una empresa -con producción de kiwis y hortalizas- que está vinculada al Grupo Saverio. En el año 2013, un directivo de Frutícola Saverio S.R.L. - empresa dedicada a la comercialización de productos provenientes de distintas zonas productivas del país y del exterior- manifestaba que uno de los objetivos del grupo era 
convertirse en un referente del kiwi en la Argentina (Cantini, 2013/2014). Se evidencia un emprendimiento que ha implantado una superficie importante de kiwi y que ha comenzado actualmente la construcción de instalaciones de empaque y frío, contando para estas inversiones con capitales que provienen de sus actividades extra-agrarias.

Por último, se destaca la presencia de un productor preexistente (proveniente de la horticultura) que con un poco más de 30 ha implantadas de kiwi ha iniciado un proceso de reconversión de su explotación, y en la actualidad redefine su estrategia de diversificación -con algunos cultivos hortícolas y arándanos-e integración de empaque y frío.

En el conjunto de los productores predomina la propiedad, que como forma de tenencia de la tierra es casi excluyente debido a que se trata de una producción a largo plazo y que muestra la poca conveniencia de adoptar regímenes de tenencia más transitorios. Solo se han encontrado unos pocos casos que explican otras formas de tenencia como arrendamiento y comodato.

Para la mayoría de los productores, el kiwi no representa su actividad principal. La inserción en actividades externas juega un rol central en lo que respecta al acceso a recursos económicos con los cuales dar inicio a la actividad agropecuaria y sostenerla hasta su entrada en régimen y a la incorporación de conocimientos de gestión productiva, de calidad y comercial.

En este cultivo la cuestión de la calidad aparece como uno de los fundamentos de la conformación de la Cámara de Productores. Como señala Craviotti (2004) en producciones de este tipo los atributos de calidad pueden ser fijados externamente o generados por los propios productores. En el sudeste bonaerense ya hay algunos productores de kiwi que han certificado normas internacionales como GlobalGap. Estas certificaciones responden a la necesidad de colocar la producción en los mercados europeos. También algunas producciones se han certificado como orgánicas. Además de las regulaciones externas, se verifica:

El intento de establecer parámetros de calidad a ser respetados localmente. Este esfuerzo implica trascender la esfera de acción de la propia explotación, estableciendo asociaciones horizontales con otros productores de la zona y con instituciones técnicas como el Instituto Nacional de Tecnología Agropecuaria (INTA) (Craviotti, 2004:30).

En este sentido, la Cámara de Productores de Kiwi de Mar del Plata junto con el INTA Balcarce desarrolló un protocolo de calidad que certifica el momento de la cosecha bajo determinados requerimientos. Los socios de la entidad cumplen con el protocolo desde el año 2013.

Otro de los aspectos a resaltar hace referencia a la importancia que adquieren las técnicas de gestión en estas producciones, que se expresa en la creciente presencia de técnicos en las explotaciones. El papel de estos técnicos excede en mucho el manejo de los aspectos estrictamente técnico-productivos, pues incluye no sólo la formulación de proyectos de inversión, sino también la búsqueda de socios para incorporar capital, la exploración de oportunidades y las alianzas estratégicas, entre otras cosas (Craviotti, 2007).

Rosenstein, Benés, Yommi, Murray y Viteri (2015) señalan que en la descripción e interpretación de las trayectorias socio-técnicas de algunas prácticas relevantes para la producción de kiwi en el sudeste bonaerense, existen diferencias en el proceso de construcción del funcionamiento de las mismas. Esas diferencias se sustentan en el involucramiento de distintos actores con diferentes estrategias, en el grado de las interacciones entre ellos, en la cercanía al discurso técnico, en los ritmos que alcanzaron los procesos de intercambio y aprendizaje, y especialmente en la capacidad de organización. Las mismas se hacen visibles, por ejemplo, en la heterogeneidad de los sistemas de conducción. Sin embargo, los mismos autores suscriben:

El proceso de las prácticas de cosecha y curado difiere profundamente de los anteriores, en tanto es el resultado de la acción colectiva. Es la innovación social, la capacidad de adoptar nuevas formas de cooperación, la que pone en marcha la innovación tecnológica, hasta lograr su estabilización. Los actores se involucran, se comprometen en la búsqueda de acuerdos (siempre parciales y temporarios) para lograr mayor calidad en el producto obtenido.

Algunos asesores técnicos visualizan un proceso de reconfiguración de agentes en un plazo no muy largo: 
Este ciclo se está terminando, se ve un grupo de productores que están medio abandonando o que venden o que están en situación de venta y, dadas las condiciones del país o no, va a surgir una etapa más profesional (Asesor Técnico de kiwi).

Está situación refiere a las posibilidades de permanencia de emprendimientos que se ubican en el primer estrato (0-10) y da cuenta de la continuidad de las empresas que hicieron grandes inversiones al inicio y de aquellos agentes que se están consolidando como productores de kiwi. Por otra parte, se visualiza que actualmente hay algunas explotaciones de kiwi que empiezan a ser manejadas por asesores especializados o por las empresas mejor posicionadas (los productores las ceden a cambio de un porcentaje de lo producido, o de un alquiler).

\section{MODALIDADES DE ORgANIZACIÓN DE LA PRODUCCióN}

En el sudeste bonaerense, como un rasgo de este cultivo se presenta la categoría de nuevos productores: los ingresantes a la producción de kiwi. Tomando en cuenta la tipología de productores de alimentos de alto valor en las áreas rururbanas elaborada por Craviotti (2008), estos agentes se aproximan en general a un proyecto empresarial, por el cual la actividad se ve como una opción de inversión que tiene como propósitos obtener ingresos complementarios a otra actividad, diversificarse o bien lograr una renta a futuro. Los niveles de inversión son variables y lo que se visualiza es que estos actores sociales se acercan más a grupos en ascenso social que canalizaron sus excedentes hacia el agro, con una gama muy amplia de matices (Bocero, 2017). Otros casos, aunque menos, refieren a situaciones más parecidas a la idea de buscar alternativas laborales.

En cuanto al análisis de las actividades extraprediales parece predominar un modelo de pluriactividad basado en esferas separadas de actividad y de ingresos, que demanda ciertos esfuerzos para compatibilizar sus diferentes requerimientos (Craviotti, 2008).

En el caso de los productores preexistentes, son pocos los productores hortícolas que, por ahora, incursionan en esta actividad debido a las elevadas inversiones requeridas.

El ciclo productivo del kiwi comienza en el mes de junio cuando las plantas son podadas en forma manual, continúa con el $\operatorname{atado}^{6}$ y en la primavera comienzan las prácticas que seguirán hasta la cosecha: raleo de flores, polinización, ${ }^{7}$ poda de verano, raleo de frutos entre otras, hasta la recolección (fines de abril, principios de mayo). En este tipo de producción las transformaciones tecnológicas se asocian con la adopción de prácticas de manejo que se efectúan manualmente.

La forma de organización del trabajo adoptada se basa en la figura del encargado o capataz y se recurre al empleo de personal permanente y temporario en distintos momentos del cultivo, en mayor cantidad en la época de cosecha pero también con demanda de mano de obra, por ejemplo, en la poda de invierno y en la polinización. En muchos casos se trata de las mismas personas, cuya contratación se prolonga en el tiempo. De acuerdo a Rosenstein, Benés, Yommi, Murray y Viteri (2015) "La relación número de hectáreas trabajadas por empleado permanente, varía entre 2,1 y 3,0 entre los productores pequeños y grandes, respectivamente”.

En las explotaciones de menos de 10 ha las actividades a cargo de los productores en forma directa son generalmente la supervisión y la compra de insumos, aunque algunos productores participan también en la poda y en tareas afectadas a la polinización. Es común la presencia de un asesor técnico.

Una organización laboral más compleja, basada en la presencia de directores técnicos e incluso asesores extranjeros, se observa en los casos de mayor tamaño y capitalización.

El administrador de una de estas explotaciones explica:

Tenemos un director técnico general de campo, que es italiano, dos ingenieros agrónomos (para fertilización, registros y certificaciones) y una directora técnica para poscosecha; y un encargado y diez empleados fijos, entre ocho y diez empleados fijos. Y después jornaleros que van entrando y saliendo para cada actividad, de acuerdo al momento del año. Son más o menos diez jornaleros que van alternado en cosecha, en poda, en raleo, pero por ahí, después de la cosecha están un mes parados, después viene la poda. Hay un grupo que es el mismo, a veces consiguen otro trabajo y se van. Se les paga por día trabajado. 
En otra explotación de similares características en cuanto a escala de producción, señalan un cambio de estrategia en la organización del trabajo, vinculada a la evolución de la plantación en términos de productividad. En principio se adjudicaban parcelas a quienes la empresa definía como trabajadores responsables por lote. Éstos se ocupaban de diferentes labores del proceso productivo y por estas tareas cobraban mensualmente un salario, a excepción de la cosecha, que se pagaba a parte. Sin embargo, como estos trabajadores no lograban llevar adelante todas las labores que demandaba el lote, se produjeron modificaciones en la estrategia. Como señala un ingeniero de la explotación, el sistema se va transformando:

Fue un sistema que se hizo hasta el año pasado para manejar el campo. Todos los trabajos de poda, atada, conducción,
controlar el riego, se daban por lote; se le daban por cantidad de lotes, son todos lotes de 1 ha; se le daban dos, tres, cuatro
lotes, depende del tiempo que quisiera trabajar cada uno, a cualquiera del personal en general, y manejaban todos los trabajos
esos, se les pagaba mensualmente. De acuerdo a la cantidad de lotes que tenías a cargo tenías un mensual por lote. Eras el
responsable de ese lote. Y a la cantidad de lotes que agarrabas era la cantidad de plata que te llevabas.

En esta modalidad quedaban incluidos hombres y mujeres. Una trabajadora que está en la empresa desde sus inicios indica: "Cuatro o cinco lotes teníamos cada uno. Los hombres tenían un poco más y las mujeres un poco menos, dos o tres lotes. Yo tenía cuatro”.

El trabajo en el lote, en muchos casos, está asociado al trabajo de distintos integrantes de la familia; así lo explicitaba otro ingeniero entrevistado: "Esto está bueno para nosotros que trabajen los matrimonios, hombre y mujer, si tiene un hijo, entonces el grupo familiar dice dame diez lotes, entonces el grupo familiar gana muy buena plata”.

Según un informante técnico, el sistema quedó en parte obsoleto durante el año 2017:

La realidad es que los encargados de los lotes no llegaban a atenderlos, entonces se empezó a poner gente por afuera, entonces se pasó a hacer todo por tanto, sobre todo en el invierno que es la época de trabajo más pesada en el campo por la poda y por la conducción.

En esta explotación, si bien hay muchas tareas que se pagan por tanto (poda, cosecha, atada, etc.) y otras por hora trabajada (por ejemplo las tareas en el empaque), lo que se observa es una combinación en la forma de organización del trabajo y en el esquema de pago según la época del año que responde a los requerimientos de trabajo.

El mismo informante refería la existencia de tres etapas en este sentido:

Un primer cuatrimestre que va de mayo a agosto, son los meses más pesados de trabajo por tanto, no sé paga por lote trabajado sino por tanto o por hora. Un segundo cuatrimestre que abarca de setiembre a diciembre, donde hay mucho trabajo por tanto y por hora. Empieza a aparecer algo de trabajo de riego, de controlar, esas cosas que empiezan a necesitar tener un responsable por cada lote. Y finalmente de enero hasta abril, que es el momento en que ya trabajo por tanto hay poco porque la poda y la atada se terminaron, y en el empaque trabajo por hora hay muy poco porque finaliza la campaña de comercialización. Entonces ahí los lotes vuelven a aparecer a un precio que en general es el doble del valor que tenían en el segundo cuatrimestre.

Por otra parte, el productor de una explotación de 30 ha mencionaba con respecto a la organización de la producción:

Es un equipo, en realidad están todos los trabajadores en todos lados, en cada campo hay digamos un líder, pero todos se juntan, todos van a todos lados; se atrasa uno de los campos, todos van a ese campo a trabajar. En pleno invierno hay días de lluvia, de mucha neblina, que no se puede podar y entonces proceso, ${ }^{8}$ agarro proceso, guardo procesado, voy vendiendo, entonces trato en lo posible de usar mi propia gente.

La estructura ocupacional que caracteriza a esta actividad se destaca por el dominio del trabajo asalariado. Entre las ocupaciones de los asalariados permanentes, las más frecuentes son las de encargado y peón general. Todos los entrevistados - productores y trabajadores- indican que no existen las relaciones de mediería en este cultivo, las cuales son comunes en la horticultura del área de estudio; pero sí es posible señalar que en algunos casos -como en los lotes asignados a los trabajadores- se visualizan algunos atributos de la misma 
resignificados a través de la condición salarial, pues los responsables del manejo de los lotes aportan la fuerza de trabajo familiar para incrementar sus ingresos.

La importancia del encargado queda evidenciada en distintos aspectos: en el manejo productivo, en el compromiso con los resultados, en la selección y reclutamiento de la mano de obra, entre otras cuestiones. Esto se hace visible tanto en las pequeñas como en las grandes explotaciones. Se pone énfasis en la polivalencia y autonomía de los encargados -flexibilidad cualitativa-, y se observa que el pago de un salario se complementa con un incentivo, en varios casos vinculado a la cosecha. Una afirmación que proviene de un asesor técnico explicita su importancia: "Tenemos un encargado general del campo, es el hombre orquesta, emperador y soldado al mismo tiempo". Incluso la idea de un estímulo para los encargados es considerada por aquellos productores que aún no tienen producción.

La mayor demanda de mano de obra en el campo se da desde mayo hasta diciembre. Fines de abril y mayo para la cosecha y luego para las tareas de poda de invierno, atado, raleo de flores y polinización.

En una de las explotaciones situadas en el tercer estrato reportan entre quince y dieciséis trabajadores permanentes y explican:

Hay un pico fuerte en cosecha y un pico fuerte en la polinización. Pero también durante todo el invierno nos estamos quedando seis o siete personas más, porque si no no llegamos con todos los trabajos que hay que hacer. Hoy tenés, casi, de mayo a diciembre, veintidós, veintitrés personas; y de enero a abril, quince, dieciocho (ingeniero agrónomo).

Las empresas que se ubican en los estratos superiores han integrado empaque y frío. Por lo tanto se observa que los mismos trabajadores que realizan las tareas en el campo están involucrados en las del empaque y van rotando por distintas actividades. Así lo explica el mismo ingeniero:

Tenemos el staff más estable, que es el que viene sí o sí todos los días, muchos de ellos viven acá en el campo. Y tienen la prioridad para los trabajos, y como son los más experimentados, por lo general mientras el tiempo permita, ahora en invierno, son los que podan todo el tiempo. Y si tenemos que procesar un día que el tiempo igual deja trabajar en el campo, la gente más nueva viene al empaque, que es un trabajo mucho más fácil de hacer y no requiere tanta expertise. Y si un día llueve, por ejemplo, y lo trabajamos en el empaque, vienen los de todo el año. Y los más temporarios son los que ese día no vienen.

Con la expresión "los más temporarios" se refiere a los que originalmente venían solamente en mayo (para la cosecha) y en noviembre (para la polinización), y que en la actualidad son demandados en otros momentos del proceso productivo ampliando los períodos de trabajo, cuya cantidad crece con el incremento de los rendimientos y de la superficie implantada.

Un trabajador permanente de la misma empresa señala:

Cuando está cerca el invierno empieza la cosecha: más o menos ahí. Termina la cosecha y después arrancamos con la poda, arreglar toda la planta, y entre medio de eso tenemos días de proceso. Cuando el día está malo estamos adentro, cuando el día está bueno estamos afuera.

Los trabajadores permanentes, en muchos casos, son oriundos de las provincias del norte del país (por ejemplo de Salta, Santiago del Estero, Corrientes, Chaco, Misiones, etc.), residentes en el área de estudio, aunque también se inserta fuerza de trabajo de origen boliviano (mano de obra dominante en las explotaciones hortícolas). Se observa predominio de hombres pero con presencia significativa de mujeres, las cuales tienen mayor inserción en los empleos temporarios.

En general, en el conjunto de los trabajadores temporarios se pueden diferenciar, por un lado, a aquellos que son contratados en reiteradas oportunidades a lo largo del año para realizar diversas tareas pero limitadas a períodos breves de tiempo: labores tales como como poda, atado, raleo de flores, polinización, cosecha, etc., y en el caso de las empresas integradas también las que se realizan en los empaques. Por otro lado, a aquellos de inserción ocasional. Neiman (2010: 6-7) señala que 
Los cambios en los mercados de trabajo temporario se hacen evidentes a partir de la creciente heterogeneidad y segmentación que van a experimentar al mismo tiempo que se diluye su carácter estacional al ser contratados repetidas veces a lo largo del año y, por lo tanto, incrementando su precariedad (Tsakoumagkos y Bendini, 1999, 2000; Ortiz y Aparicio, 2006).

El encargado de un kiwal del primer estrato reseña:

Para la polinización se ocupan siete u ocho mujeres en un tiempo de una semana, alrededor de diez días. Por ejemplo, el martes tuvimos once mujeres. De acá a veinte días, aproximadamente, estas mujeres vuelven nuevamente porque es necesario aplicar una hormona que se pasa fruto por fruto. ${ }^{?}$ Luego para la cosecha pueden venir las mismas, muchas son de acá del barrio, de San Carlos. Son changas para ellas.

Asimismo el encargado de una de las empresas de perfil agroindustrial señala:

Eventuales fundamentalmente en la cosecha, en la poda en invierno que es muy fuerte, o sea mayo, junio, julio, agosto, setiembre. Damos trabajo en el empaque que es eventual también, son pocos meses en el año. En el empaque el trabajo puede llegar hasta diciembre.

Con respecto a si existen tareas diferenciadas para hombres y mujeres, en general las mujeres participan en la mayor parte de los trabajos en el campo, y solamente pueden quedar excluidas de aquellas labores puntuales que requieren mayor fuerza física. En los empaques, se nota un predominio de las mismas en la ejecución de las tareas manuales de selección de la fruta.

En el trabajo temporario se diferencian los casos en los cuales la empresa contrata directamente a los trabajadores transitorios de algunas situaciones en las que se recurre a intermediarios de mano de obra (pseudo-cooperativas de trabajo, agentes de contratación eventual, etc.). Habitualmente los trabajadores provienen del área de estudio, de las localidades que están en las proximidades de las explotaciones (Batán, El Boquerón, La Gloria, Santa Paula, Nicanor Otamendi, Miramar, Balcarce, etc.).

Existen intermediaciones en el vínculo laboral -como es posible observar en el siguiente caso- en el reclutamiento, la movilidad y la organización del trabajo:

Hay un señor que tiene su combi y empezó a juntar a la gente, a hacer una cuadrilla, y le cobra a la empresa una extra parece por traerle a la gente. Él va, junta ponéle..., necesitamos ocho, diez; él va, junta del barrio y la trae. Trae a granel parece. Le da la combi a un muchacho y él trae el personal y él le cobra también al personal. Cobra de los dos lados. (Trabajador en explotación de kiwi)

También es común que en las contrataciones adquieran importancia las redes informales conformadas a partir de vínculos de parentesco y amistad. Testimonios de los productores así lo expresaban: "Y cuando hay que traer gente viene la cuñada, la hermana del encargado, la prima, el primo".

Un productor del primer estrato refería:

Los transitorios son bolivianos que viven cerca. Por ejemplo, nosotros tenemos cerca el frutillar ${ }^{10}$ que tiene mucha gente, entonces muchas veces vamos ahí, hablamos con alguno de los chicos que están de encargados y le decimos: ¿tenés alguien que no esté trabajando?, y ellos mismos nos mandan gente del mismo frutillar o gente de la zona que ya lo conocen al encargado. Hay mucha gente ahí que hace changas.

Con respecto a la experiencia en el trabajo agrario, no todos los trabajadores provienen de la actividad. En este sentido, una trabajadora comentaba:

De acá de la zona vienen de Otamendi, de El Boquerón, de Batán. Algunos con cero experiencia en el campo. Vienen pocos que han trabajado en kiwi, un poco más que han trabajado en quinta, eso es la mitad o un poco menos de la gente que viene. $Y$ el resto viene que nunca ha trabajado en el campo. Vienen algunos de Otamendi que han maleteado papa. De los temporarios, si vienen nueve o diez, capaz que cuatro o cinco nunca trabajaron en el campo.

Las empresas integradas son las que tienen un número mayor de trabajadores registrados, en lo cual influye su mayor exposición a la fiscalización laboral o bien el hecho de que certifican sus productos (con normas GlobalGap) para alcanzar el mercado internacional; pero 
Incluso en el mejor de los escenarios, el registro de las ocupaciones no implica el "blanqueo" del total de los salarios, ya que las empresas pueden realizar aportes que cubran sólo algunos de los días trabajados (Quaranta \& Fabio, 2011:219).

O una menor cantidad de horas que las efectivamente trabajadas.

La incorporación de normas de calidad o un proceso de certificación de las mismas mejoran aspectos de las condiciones laborales como la infraestructura sanitaria en los lugares de trabajo y la obligación de tomar precauciones en el uso de agroquímicos, teniendo en cuenta

(...) solo parcialmente aspectos referidos a la calidad de las ocupaciones, centrándose en cuestiones referidas a la seguridad e higiene del trabajo y considerando marginalmente aspectos referidos a la forma de contratación de la mano de obra (Quaranta, 2011:220).

\section{CONSIDERACIONES FINALES}

El presente trabajo procura mostrar la construcción de un nuevo y complejo entramado productivo y comercial en el sudeste bonaerense, a través de la expansión de un cultivo global como el kiwi. Así, es posible observar el ingreso de nuevos productores, la presencia desde pequeos inversores hasta agentes que están insertos en mltiples espacios de acumulación, la existencia de empresas integradas y de asesores especializados, la incorporación de criterios de calidad y la inserción de capitales extra-locales y extra-agrarios.

Por otra parte, desde el punto de vista de la organización de la producción se observa el uso flexible de la fuerza de trabajo, con mecanismos de flexibilidad cuantitativa -contrataciones temporales, pago a destajo, etc.- y con la incorporación de modalidades de flexibilidad cualitativa en aquellas tareas que necesitan de una mayor implicación y autonomía en el trabajo, como en el caso de los encargados de las explotaciones. Se advierten mejoras parciales de las condiciones laborales, ligadas fundamentalmente a la incorporación de normas de calidad, pero se mantienen formas precarias del empleo en términos contractuales y/o salariales.

Por último, distintas señales muestran que probablemente la conformación de la etapa de expansión indicada esté dando paso a un nuevo escenario, signado por la reconfiguración de los agentes productivos.

\section{ReFERENCIAS BIBLIOGRÁfiCAS}

Albornoz, F., Milesi, D. \& Yoguel, G. (2004). Tramas productivas en viejos sectores: metodología y evidencia en la Argentina. Desarrollo Económico, vol. 43 (n.172), pp. 545-571.

Becattini, G. (1992). El distrito industrial marshalliano como concepto socioeconómico. En Pyke, F. Becattini, G. \& Sengenberger, W. (Comps.) Los distritos industriales y las pequeñas empresas (pp.61-79). Madrid: Ministerio de Trabajo y Seguridad Social

Bocero, S. (2017). Nuevas configuraciones productivas: El cultivo de kiwi en el sudeste bonaerense. En Ramirez, M. (Comp.) VI Congreso Nacional de Geografía de Universidades Públicas-República Argentina. Corrientes: Universidad Nacional del Nordeste.

Bocero S. \& Bonnet, A. (2018) Nuevos entramados socio-territoriales: la producción de kiwi en el sudeste bonaerense. En García, M. (Comp.) Geografía, espacio y sociedad en los debates actuales: I Jornadas Nacionales de Geografía de la UNMDP (pp.91-106). Mar del Plata: UNMDP.

Cantini, J. (2013-2014). Análisis y perspectivas. Anuario Market 2013/2014, Año 8 (n.8), 30-31.Recuperado de http s://issuu.com/edicionesfrutihorticolas/docs/anuario_frutihorticola_2013_2014

Craviotti, C. (2004). Calidad, coordinación entre agentes, y organización del trabajo en las producciones no tradicionales. Agroalimentaria, vol. 10 (n.18), pp.23-33.

Craviotti, C. (2007). Agentes extrasectoriales y transformaciones recientes en el agro argentino. Revista de la CEPAL (n. 92), pp. 163-174. Recuperado de https://www.cepal.org/es/publicaciones/11199-agentes-extrasectoriales-t ransformaciones-recientes-agro-argentino 
Craviotti, C. (2008). Los nuevos productores: alimentos de alto valor y reestructuraciones agrarias. Buenos Aires: Ediciones CICCUS.

Craviotti, C. (2012). Los cambiantes territorios del sistema global de frutas frescas y sus implicancias a nivel agrario. La producción del arándano en Entre Ríos. En Craviotti, C. (Coord.) Tramas productivas y agentes sociales en la fruticultura globalizada (pp.143-167). Buenos Aires: Miño y Dávila.

Gereffi, G.; Humphrey, J. \& Sturgeon, T. (2005). The governance of global value chains: An analytic framework. Review of International Political Economy,vol.12 (n.1), pp. 78-104.

Neiman, G. (2010). Los estudios sobre el trabajo agrario en la última década: una revisión para el caso argentino. Mundo Agrario, vol. 10 (n.20), pp.1-20. Recuperado de https://www.mundoagrario.unlp.edu.ar/article/view/ v10n20a20

Patagonian Fruits Trade S.A. Productos. Kiwi. http://patagonianfruits.com/kiwi/ [consulta: 5 de junio de 2017].

Quaranta, G. (2011). Organización laboral y precariedad ocupacional en la producción de uva de mesa de exportación, Provincia de San Juan (Argentina). En Mastrangelo, A. \& Trpin, V. (Comp.) Entre chacras y plantaciones: trabajo rural y territorio en producciones que Argentina exporta (pp. 201-223). Buenos Aires: CICCUS.

Quaranta, G. \& Fabio, F. (2011). Intermediación laboral y mercados de trabajo en agriculturas reestructuradas: el caso del Valle de Uco, Mendoza, Argentina. Región y Sociedad, vol. XXIII (n. 51), pp. 193-225. Recuperado de htt p://www.scielo.org.mx/pdf/regsoc/v23n51/v23n51a7.pdf

Radonich, M., Steimbreger, N. \& Kreiter, A. (2005). Tramas sociales y organización de la fruticultura en áreas de expansión. En 1 ras Jornadas de Antropología rural, Tucumán.

Rosenstein, S.; Benés, G.; Yommi, A.; Murray, R. \& Viteri, L. (2015). La construcción de la innovación en la producción de kiwi del sudeste de la provincia de Buenos Aires. En IX Jornadas Interdisciplinarias de Estudios Agrarios y Agroindustriales Argentinos y Latinoamericanos. Recuperado de http://www.ciea.com.ar

\section{Notas}

1 El cultivo de kiwi comienza en la Argentina en los años ochenta, con avances y retrocesos, intentos y postergaciones. Las primeras producciones comenzaron a comercializarse en plena etapa de la convertibilidad, situación que frenó la posibilidad de exportar. El mercado local y mundial daban cuenta de kiwis procedentes de Chile, Nueva Zelanda e Italia, y el precio de un solo kiwi era tan alto que se lo comenzó a llamar "el oro verde". Sumado a esto se hicieron evidentes las deficiencias en el manejo de los primeros asesores técnicos, productores y viveros que introdujeron el cultivo (Bocero, 2017). Una intensa campaña ligada a sus propiedades nutricionales ha sido un elemento dinamizador del consumo de esta fruta en el mercado doméstico.

2 Proyecto de Investigación (Código 15/F631), Facultad de Humanidades, UNMDP. Período 01/01/18-31/12/19. El proyecto de investigación se propone analizar la dinámica social que produce y redefine los espacios agrarios en el sudeste de la provincia de Buenos Aires, focalizando en el estudio de las relaciones entre los actores individuales, colectivos e institucionales, que en los casos del kiwi y de las frutas finas le otorgan especificidad al territorio.

3 Este apartado se basa en Bocero (2017) y Bocero \& Bonnet (2018).

4 La unidad económica estimada por productores y asesores técnicos para el área de estudio oscila entre 6 y 8 ha.

5 Kiwi Tre Castelli Soc. Agr. DI Righetti Roberto \& C.S.S., Verona (Italia).

6 Atado: se atan las ramas a la estructura que sostiene a la planta para obtener un esquema ordenado que permite mayor ventilación, entrada adecuada de luz y buena distribución de los frutos.

7 La polinización aparece como un tema clave ya que repercute en el tamaño del fruto. En la mayoría de los casos se realiza polinización artificial manual (por asperjado de polen). También se combinan distintas técnicas en simultáneo, como artificial y polinización por abejas

8 Se refiere a las tareas de acondicionamiento posteriores a la cosecha que se realizan en el empaque para su comercialización (cepillado, selección, calibrado, embalado).

9 Se trata de la aplicación de un regulador de crecimiento que incrementa el tamaño del fruto y mejora su calidad.

10 Se refiere a una empresa agroindustrial productora y exportadora de frutas frescas y congeladas, ubicada en el partido de General Pueyrredon. 